\title{
ЛОГИСТИЧЕСКИЕ ИННОВАЦИИ СЕЛЬСКИХ ТЕРРИТОРИЙ "
}

\author{
(c) 2019 Потехина Елена Николаевна \\ кандидат экономических наук, доцент \\ Марийский государственный университет, Россия, Йошкар-Ола \\ E-mail: vilor@mail.ru
}

В статье рассмотрены перспективы инновационных трансформаций в сельском хозяйстве сквозь призму международного тренда ведения практики и российского опыта.

Ключевые слова: инновации, сельское хозяйство, логистика, сельские поселения.

В условиях приоритета неограниченности человеческих потребностей как мирового современного тренда развития общества с одной стороны и ограниченности природных ресурсов с другой, сформировалась объективная предпосылка перехода экономики на инновационный путь развития. Инновации всегда сопровождали развитие цивилизации и являлись неотъемлемой частью развития человечества. Переход ведущих стран к инновационной экономике, основанной на знаниях, является основой современного мирового инновационного общества.

Предприятия малого и среднего бизнеса активно интегрируются в глобальный тренд. Ограниченность в финансовых, человеческих, производственных ресурсах толкает малые предприятия к поиску альтернативных способов привлечения инноваций через акселерации и стартапы. Возможны собственные разработки в части усовершенствования производственного процесса, способствующие снижению себестоимости продукции. Сотрудничество с вузами позволяет предприятиям найти неординарные решения и возможности, найти перспективного молодого специалиста. Для сельского хозяйства России инновационно-ориентированный путь социально-экономического развития является актуальной перспективой развития современных технологий, производящую высокую долю добавленной стоимости.

Инновации в сельском хозяйстве являются неотъемлемой частью развития агропромышленного комплекса.

Необходимость инноваций в малых предприятиях сельского хозяйства обусловлена следующими параметрами:

- развитие новых бизнес-идей;
- формирования культа изменений;

- мотивация персонала;

- возможность новых способов заработка;

- PR (информационные потоки с целью создания конкурентоспособного имиджа предприятия).

Развитие агрохолдингов в России способствует развитию сельскохозяйственных территорий, расширяя свою производственнохозяйственную деятельность, привлекают дополнительные инвестиции, развивают и внедряют инновационные технологии. Согласно данным российский фонд венчурных инвестиций, учреждённого Агентством стратегических инициатив в 2019 году треть российских сельскохозяйственных предприятий используют технологии посредством интернет, позволяющие объединить по средствам интернет различные устройства, в связи с этим делается вывод, что предприятия используют систему интернет вещей (IоT). Использование больших данных является актуальной задачей для сельского хозяйства, при этом основной проблемой остается интерпретация полученных данных. Согласно «дорожной карте» к 2020 году 30\% российских сельхозяйственных предприятий будут использовать инновационные достижения в области беспилотной техники, сенсоры и датчики для дальнейшего развития интеллектуальной фермы, технологии интернета вещей (IoT).

Развитие технологий позволяет расширить информационный поток поступающий с различных мобильных устройств, онлайн-приложений датчиков, агротехники, метеорологических станций, дронов, спутников, внешних систем, партнерских платформ, открытых источников, от поставщиков и покупателей, тем самым

\footnotetext{
* Исследования поддержаны грантом РФФИ 19-410-120005 р_а «Оценка перспектив развития сельских территорий Республики Марий Эл за счет развития несельскохозяйственных видов деятельности»
} 
создает возможность принимать правильные управленческие решения для прогнозирования урожай (внесение удобрений, увлажнения почвы, сроки посадки и посева в растениеводстве, сроки погрузочно-разгрузочных работ до покупателя, соблюдение температурного режима).

Агрохолдинги используют широкий спектр технологий агрегированных с помощью приложений для получения широкого спектра данных: датчики параметров почвы для анализа и контроля влажности, кислотности, датчики мониторинга роста и состояния растения, системы умного орошения, анализ погоды и состояния растений и т.д.

С помощью анализа больших данных в растениеводстве производится мониторинг состояния урожая, прогнозируются оптимальные сроки посадки, полива, внесения удобрения, уборки урожая.

Интерпретация собственных разработок в малых сельскохозяйственных предприятиях в первую очередь в основном направлена на совершенствование имеющихся технологий, доработку и усовершенствование, приспособление на малые объемы.

ООО «Агроноут», участник проекта российского инновационного центра «Сколково», осуществляет разработки, позволяющие сельскохозяйственным машинам менять дозы удобрений, подбирая их под конкретнык участки полей для дифференцированного внесения удобрений. Технология распределения участков поля по коэффициентам плодородности может использоваться на любых землях. Запущен пилотный проект в агрохолдинге «Кубань».

Роботизированные комплексы с полным циклом автоматизации в сельском хозяйстве характерны для перерабатывающих комплексов. В России роботизированный монопродуктовый завод по производству сырокопченой колбасы группы «Черкизово» в городе Кашира Московская область показал свою эффективность, на предприятие занято 150 человек вместо 700 человек на аналогичной мощностях в традиционном производстве.

Согласно исследованиям, проведенным в 2017 году глобальной экспертной группы Digital McKinsey McKinsey, сельское хозяйство находится на четвертом месте среди всех отраслей экономики по возможности автоматизации. В АПК активно инвестируют средства технологические компании и инвесторы.
Международные компания активно разрабатывают инновационные технологии для сельского хозяйства. Страны Евросоюза одни из первых занимаются разработкой и используют современные технологии в агропромышленном комплексе.

Крупная компания John Deere разрабатывает сельскохозяйственную технику и оборудование в том числе технологии точного земледелия, тракторы, комбайны, жатки для зерноуборочные комбайны, кормоуборочные комбайны, опрыскиватели, посевную технику, самоходные косилки и жатки.

Роботы для прополки и прореживания сорняков компания EcoRobotix. Ориентировочная цена 1 миллион рублей. Компания Bosch совместно с компанией Bayer разрабатывает высокоэффективные сенсорные технологии, занимается созданием программ принятия аналитических решений и выборочной системы распыления средств защиты растений на базе искусственного интеллекта.

Роботизированными системами точного опрыскивания, инжиниринговая компания Agrointelli Дания работают над. Основная проблема инноваций в сельском хозяйстве связана с их разрозненностью и слабой возможностью интеграции многочисленных инноваций.

Снижение себестоимости за счет использования автоматизации и отказа от использования ручного труда по разным оценкам колеблется от 5 до 15 процентов. При этом не учитывается весь спектр затрат по разработке и внедрению технологий. Внедрение технологий возможно только в адаптивной системе управления с полным циклом автоматизации бизнес-процессов. Для этого одним из необходимых условий является интеграция в единой цифровой платформе всех технологических процессов в единую систему и единой базы фермеров, производителей сельскохозяйственной техники, производителей удобрений, агрономов, логистических операторов. Использование технологий блокчейн для мониторинга разрабатывается и внедряется немецкой компанией «SAP SE» проекта «Ферма к потребителю». на основе блокчейн.

Существуют объективные предпосылки для внедрения инновационных технологий в сельское хозяйство. Тестирование и разработка инновационных идей моделирование будущих продуктов с привлечением программистов, дизайнеров, менеджеров проходит с помощью ин- 
струмента корпоративных идей Хакатон.

Для внедрения инновационных технологий необходимым условием является стратегическое мышление руководителей и сотрудников предприятия, творческий подход к решению стандартных решений. В настоящее во всем мире ведётся активная работа по внедрения инновационных решений в производственный процесс. Инновации внедряются точечно и требуют масштабирования, точной настройки в действующую систему, являющуюся базисом, адаптирующуюся под внешним воздействием. Проходя все стадии лабораторных исследований, пилотного проектов, инновационные технологии внедряются в производственный процесс. От формулирования инновационной идеи до получения желаемого экономического эффекта проходит несколько этапов с жестко регламентированными сроками, при этом четкая слаженная работа всех участников является необходимым условием продвижения и поддержки инновации на всех уровнях.

Автоматизация и снижение доли ручного рутинного труда, позволяющие снизить трудозатраты и повысить эффективность отдельных бизнес-процессов влечет за собой потребность в квалифицированных кадрах, дополнительном обучение персонала актуальным компетенциям. Отток трудоспособного населения из сельской местности, недостаток в квалифицированных кадрах связан с глобальными процессами. При этом существует обратный поток. Решить данную проблему возможно в том числе путем вы- страивания грамотных логистических потоков. Необходимо развивать инфраструктурную составляющую сельских поселений, что позволит вывести экономику на новый инновационный уровень. Децентрализованная логистическая система не позволяет осуществлять работу в едином информационном пространстве, не обладает прозрачностью материальных и информационных потоков.

По мнению зарубежных ученых, логистические системы применимые как в частных коммерческих предприятиях, так и на государственном уровне, являются инструментом интегрированного управления материальными и связанными с ними информационными, финансовыми потоками с целью оптимизации затрат и достижения максимального экономического эффекта.

В сельском хозяйстве инновационный путь развития не возможен без учета существующей практики не учитывающей всей совокупности проблем, связанных с управлением транспортными логистическими потоками.

Системы планирования, анализа и контроля кадров; планирования, анализа и контроля грузов; планирования, анализа и контроля автопарка интегрированные в действующую информационную систему, выстроенные с учетом действующего законодательства, позволит предприятиям сельского хозяйства использовать конкурентные преимущества при осуществлении эффективной финансово-хозяйственной деятельности в решении актуальных задач.

\section{Библиографический список}

1. Потехина Е.Н. Концептуальная модель инновационной устойчивости логистической деятельности // Инновационное развитие экономики. - 2017. - № 6(42). - С. 145-148.

2. Потехина Е.Н. Факторы инновационной устойчивости и их влияние на логистическую деятельность // Инновационное развитие экономики. - 2017. № 6(42).- С. 149-151.

3. Российская Федерация. Законы. Конституция Российской Федерации [Электронный ресурс]: принята всенародным голосование 12 декабря 1993 года (в ред. федер. Конституционных законов от 30 декабря 2008 № 6-ФКЗ и № 8 - ФКЗ) // СПС «Консультант плюс»

4. Российская Федерация. Гражданский кодекс Российской Федерации: часть первая [Электронный ресурс]: федер. закон № 51-ФЗ 30.11.94: принят ГД ФС РФ 21.10.1994: по состоянию на 07.11.2019 г. // СПС «Консультант плюс»

5. Российская Федерация. Законы. Об общих принципах организации местного самоуправления в Российской Федерации [Электронный ресурс]: федер. закон № 131-Ф3 от 06.10.2003 N131-Ф3 (ред. от 02.08.2019): по состоянию на 07.11.2019 г. // СПС «Консультант плюс» 